Special issue on Max Charlesworth: Crossing the Philosophy and Religion Divide

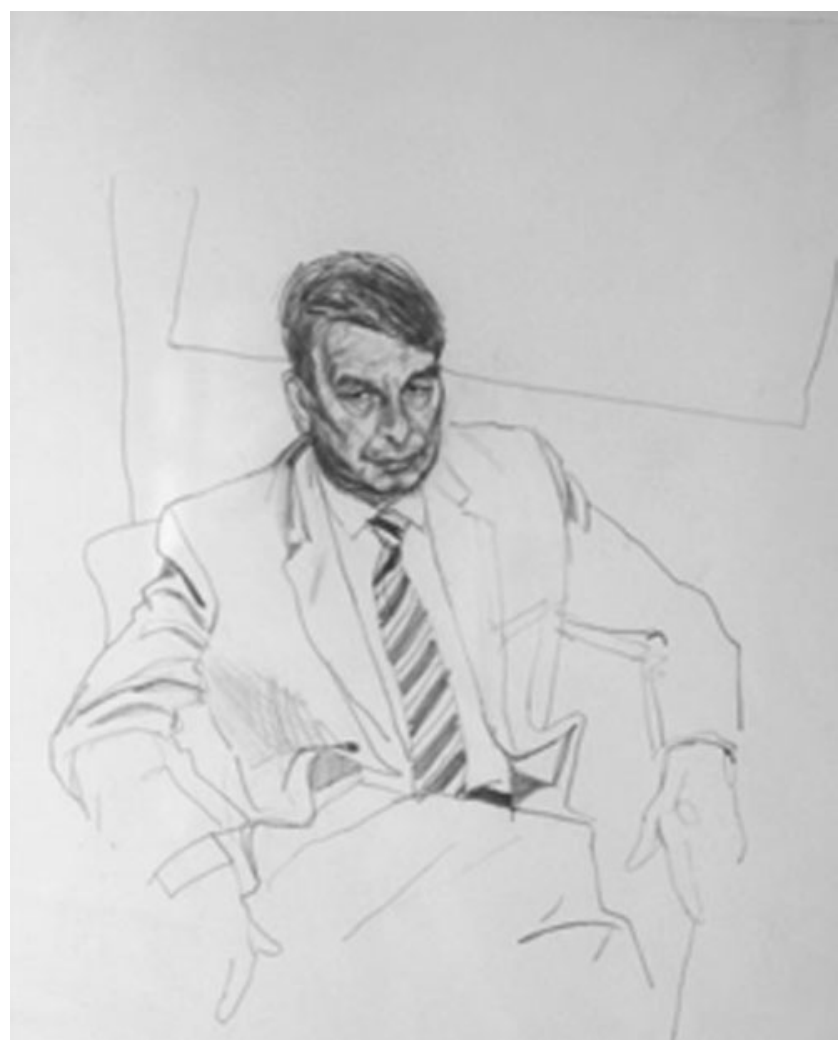

Max Charlesworth by Lewis Miller (courtesy of the Charlesworth family) 


\title{
In the Beginning... was a cyclostyled Sophia
}

\author{
Patrick Hutchings
}

Published online: 27 December 2012

(C) Springer Science+Business Media Dordrecht 2012

Sophia was founded in 1962 by Max Charlesworth, then a lecturer in Philosophy at the University of Melbourne. It was first issued in a cyclostyled format, rather like lecture note handouts. Despite its humble appearance, Max secured in the inaugural issue articles by such eminent philosophers as Peter Geach, A. Boyce Gibson, Dom Illtyd Trethowan, G.E. de Graaf and Ninian Smart.

Sophia has now grown into an international journal published for a period by Ashgate in the UK, currently by Springer in The Netherlands. Its growth has been due in considerable measure to the editorship of Purushottama Bilimoria-currently of University of California at Berkely whose wide academic contacts, met at the many conferences that he attends, and institutions he visits internationally, have brought us numbers of quality contributions and editorial connections.

Some time ago Prof. Emeritus M.J. Charlesworth, A.O., Founding Dean of Humanities of Deakin University, sent in to Sophia a most interesting paper on the philosophy of religion. It seemed to the editors an apt occasion on which to ask former colleagues and protégés of Max's to send in articles for a kind of philosophical-literary bouquet for him. This is this issue.

We offer our congratulations to Max Charlesworth for his so fruitful notion: the founding of Sophia.

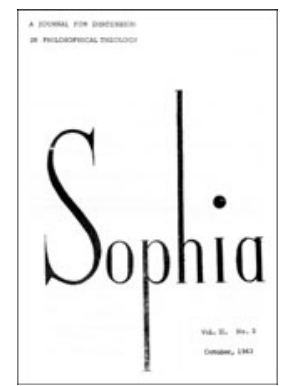

Patrick Hutchings, on behalf of all at Sophia.

P. Hutchings $(\square)$

Melbourne University, P O Box 4230, Melbourne, VIC 3052, Australia

e-mail: sophia@philosophy.unimelb.edu.au 